\title{
Ethnic Identity, Individual Identity, and Perceived Stress Correlated with Life Satisfaction of American College Students
}

\author{
Yueh-Ting Lee ${ }^{1, *}$, Rongling Tang1, Aarren Minneyfield ${ }^{1}$, Jennifer Brantley ${ }^{1}$, Wenting Chen ${ }^{2}$ \\ ${ }^{1}$ School of Psychological and Behavioral Sciences, Southern Illinois University, Carbondale, Illinois, USA. \\ ${ }^{2}$ Department of the College English Education, Capital Normal University, Beijing, China.
}

\begin{abstract}
How to cite this paper: Yueh-Ting Lee, Rongling Tang, Aarren Minneyfield, Jennifer Brantley, Wenting Chen. (2021). Ethnic Identity, Individual Identity, and Perceived Stress Correlated with Life Satisfaction of American College Students. The Educational Review, USA, 5(12), 470-477.

DOI: $10.26855 /$ er.2021.12.003
\end{abstract}

Received: November 12, 2021

Accepted: December 6, 2021

Published: December 28, 2021

Corresponding author: Yueh-Ting Lee, School of Psychological and Behavioral Sciences, Southern Illinois University, Carbondale, Illinois, USA.

Email: leey@siu.edu

\begin{abstract}
On the basis of previous and recent research on college life and school education it is hypothesized that both individual or personal identity (i.e., individual self-esteem) and ethnic or social identity (i.e., group/collective self-esteem) play a very important role in life satisfaction of college students. A total of 186 college students completed different inventories containing items concerning life satisfaction. The results revealed that individual or personal identity, ethnic or social identity, and perceived stress largely accounted for the variance of college students' life satisfaction. In addition, the differences between White or Euro-American, Hispanic/Latino/a, African, Asian, and other students were also found to be significant in terms of their college life satisfaction, personal identity, social identity, locus of control, residence or living conditions, and pessimistic attitudes toward racial problems.
\end{abstract}

Keywords

Ethnic Identity, Personal Identity, College Life Satisfaction, Perceived Stress

\section{Introduction}

Many studies (e.g., Aspinwall \& S. Taylor, 1992; Crocker \& Wolfe, 2001; Crocker, 2002; Lee \& Seligman, 1997; Mooney, Sherman, \& Presto, 1991) revealed that locus of control, self-esteem, optimism, stress and coping, and perceived physical distance was predictors of college adjustment and performance. This may be true in terms of individual differences. However, their studies did not account for social interaction and cultural identity as a part of college life adjustment and satisfaction. The current study attempts to extend their research by considering a social factor (e.g., group or cultural identity) as one of the predictors.

\subsection{Social and Cultural Factors are of Importance at American Colleges}

Wherever one goes, he or she can hardly see a homogeneous body of college students in any American institution. Though the majority college students, by and large, are European/Caucasian whites, there is a great increase in non-majority students such as African Americans, Hispanic/Latino Americans, Asian Americans, American Indians, and many other international students (e.g., Yau, Sue, \& Hayden, 1992) with their corresponding student organizations and clubs (see Wang, Sedlacek, \& Westbrook, 1992; also see Rule \& Sutherland, 2017). Various ethnic groups may tend to maintain their own cultural heritage and values.

According to Tajfel and Turner (Tajfel, 1981; Tajfel \& Turner, 1986), social identity theory claims that members of a 
social group are motivated to be distinctive from members of other groups so as to maintain a positive image for their group. This theory includes the self-concept which has two distinct parts: personal identity and social identity. Personal identity denotes specific attributes of the individual such as feelings of competence, psychological traits, and personal values (e.g., individual self-esteem). Social identity, on the other hand, is defined as "that part of an individual's self-concept which derives from his knowledge of his membership of a social group (groups) together with the value and emotional significance of that membership" (Tajfel, 1981, p. 255). Ostensibly, ethnically different students tend to maintain and protect not only their personal identity (e.g., individual self-esteem) but also their distinctive cultures, values, and positive group image (i.e., social identity or collective self-esteem).

\subsection{Melting Pot and Political Philosophy}

The American "melting pot” philosophy seems, however, to be inconsistent with Tajfel's social identity theory above. According to Taylor and Porter (1994), "the political philosophy in the United States has been, and still is to some extent, based on the premise that members of a cultural group should give up their inherited culture when they come to the United States and become 'American'” (p. 87). In other words, all the cultures in America get stirred into the same great pot until cultural differences are boiled away and only one single culture remains - the dominant white American one. It is possible that motivation for social identity and cultural diversity on campuses may raise some conflicts between students.

For example, Berger (1989) reported that in the late 1980s, there were episodes of racist graffiti, jokes, anonymous hate notes or brawls at 175 American campuses, including top private colleges like Brown University, Smith College, and Colby College, as well as at public universities like Michigan and Wisconsin. These incidents have ranged from the racist hate notes received by four black women at Smith college, to racial jokes broadcast on the university radio station at the University of Michigan, to an attack on a black student at the University of Massachusetts.

According to Lee (1994), one of the explanations for those conflicts on campuses may be related to symbolic values and social identity. Some research (see McConahay \& Hough, 1976; Sears, 1988; Sears et al., 1986) showed that racial conflict may be related to issues such as "symbolic racism" and "modern racism", (e.g., indicated by agreement with the following type statements: "minorities push too much for their rights", "they do not have our values", "it is easy to understand the anger of black people in America”, etc.). If a culturally dominated group interferes with the symbols and values of a dominant group, conflicts may occur. Research suggests that minority and nonminority students indeed have different values and attitudes toward social problems (Fisher, Fisher, Arsenault, Jacob, \& Najor, 2020; Lee, 1993a; Lee \& Holt, 2019; Lee \& Zhao, 2019; Tajfel, 1981). Explicitly, racial conflict on campuses may be due to the fact that the minority students on campus tend to maintain their own cultural symbols and values (e.g., Black music, Hispanic festivals), which could interfere with the symbols of the nonminority students. Therefore, social identity (including symbolic values) for racial groups on campuses may play an important role in college life satisfaction.

\subsection{Empirical Research on Social and Personal Identity}

As social animals (Aronson, 1992), individuals influence and are influenced by each other. Furthermore, in line with social identity theory, many psychologists (Brewer, 1991; Brown, 1988; Crocker \& Luhtanen, 1990; Lee \& Ottati, 1993; Tajfel, 1982; D. Taylor \& Dube, 1986; D. Taylor, Wright, Moghaddam, \& Lalonde, 1990) predicted and found that people are motivated to maintain both personal identity, (e.g., individual self-esteem) and group/social identity (e.g., collective self-esteem including group membership awareness, positive group image, and pride of one's group). Their research has been restricted to, and supported by, the areas of personality and social psychology. In other words, social identity theory has not been applied elsewhere. Thus, the current study focuses on college life satisfaction by applying social identity theory to the area of college student counseling and development.

Summary. In sum, based on the discussion above, the present study hypothesizes that both personal identity and social identity account for a significant portion of the variance of college life satisfaction. However, a cautionary note is in order. Because previous studies (see Aspinwall \& S. Taylor, 1992; Mooney, Sherman, \& Presto, 1991) suggest that individual (or non-social) factors such as stress and campus living conditions were related to college life satisfaction, it is certainly reasonable to say that those individual (or non-social) factors may also influence life satisfaction among college students.

\section{Method}

\subsection{Participants}

A total of 186 students from two American colleges on the East coast participated in the study. There were 117 females and 69 males. The average age was 21.81. One hundred and two were White students; 21 Hispanic and Black 
Students, 37 Asians, and 26 others. Education levels represented were: 17 freshmen and sophomores, 38 juniors, 36 seniors, and 58 other (e.g., graduate students). There were a variety of majors represented in the sample, such as: chemistry, physics, engineering, psychology, linguistics, sociology, business, humanities, and other disciplines.

\subsection{Instruments and Materials}

The dependent or predicted variable was life satisfaction which was measured using Cantril's inventory (1965). The following were selected for use as predictors of college life satisfaction.

- $\quad$ Personal identity (i.e., individual self-esteem), assessed by Self-Esteem Scale (Rosenberg, 1965).

- $\quad$ Social identity (i.e., collective self-esteem), measured by Crocker and Luhtanen's Collective Self-Esteem Scale (1990, Luhtanen \& Crocker, 1992).

- College Student Stress assessed using The Perceived Stress Scale (PSS) (Cohen, Kamarck, \& Mermelstein, 1983).

- $\quad$ Locus of control, measured by James’ Internal-External Locus of Control Scale (1957).

Students were also asked about their attitudes toward the future of racism. Two questions were asked to measure anti-racist pessimism (i.e., a negative or pessimistic attitude toward reducing racism and solving racial problems). They were:

(1) "Discrimination and stereotypes are stable and permanent," and

(2) "We will never completely get rid of discrimination. It is part of human nature."

Two more questions were asked to measure anti-racist optimism (i.e., a positive or optimistic attitude toward reducing racism and solving racial problems). They were:

(1) "The best way to overcome discrimination and prejudice is through social pressure and action;"

(2) "Minority people will be less discriminated or stereotyped in American society in the future than now."

Students' responses to the questions in all the measures above were indicated on seven-point scales—ranging from 1 (strongly disagree) to 7 (strongly agree). Other questions were also included to measure aspects of students' residential life (e.g., noise-quietness level, adequate space, hygiene level, living utility conditions, interpersonal relationship with other residents, and residential social life). Finally, students' demographic information was collected (e.g., age, gender, and education).

\subsection{Procedures}

All instruments were administered in a traditional paper-and-pencil method. A set of the various inventories and scales were handed out to participants. About $80 \%$ of the students completed their survey in a psychology course as a part of course requirements. The rest of the participants completed their materials outside of class. All participants were thanked and debriefed upon completion of the materials.

\section{Results}

\subsection{Internal Consistency and Reliability of Scales}

Reliability scores for all instruments were obtained by alpha coefficients (Cronbach, 1951). The Cronbach coefficient alpha for the life satisfaction or content measure (i.e., Cantril's inventory) was 0.72 (9 items). The alpha for the personal identity (or self-esteem) measure (i.e., 10 self-esteem items) was 0.89; for the social identity or collective self-esteem measure (16 items) was 0.92; for the Perceived Stress Scale (PSS) was 0.77; for the locus of control scale (i.e., Internal-External Locus of Control Measure) was 0.84 (30 items); for the questions of residential life conditions (9 items) was 0.92 . Generally, these scales had very good internal consistency.

\subsection{Basic Intercorrelations}

The data in Table 1 (see Table 1) revealed that college life satisfaction (i.e., content) was significantly correlated with individual self-esteem (or personal identity), $r=0.64, p<0.0001$, two-tailed, with collective self-esteem (or social identity), $r=0.33, p<0.001$, two-tailed, and with residential conditions $r=0.25, \mathrm{p}<0.001$, two-tailed. On the other hand, college life satisfaction (i.e., content) was negatively correlated both with external control, $r=-0.21, p<0.01$, two-tailed; and with stress, $r=-0.34, p<0.001$, two-tailed. In other words, greater personal identity, social identity, and better residential conditions made college students feel more satisfied with college life while less internal control (or more external control), and more stress made them feel less satisfied with their college life, as expected. 
Table 1. Means, Standard Deviations and Intercorrelations

\begin{tabular}{lcccccccccc}
\hline & Mean & SD & 1 & 2 & 3 & 4 & 5 & 6 & 7 & 8 \\
\hline 1.Satisfy & 44.94 & 6.79 & 1.00 & & & & & & & \\
2.External & 113.6 & 20.08 & $-0.21^{* *}$ & 1.00 & & & & & & \\
3.Racial Pes. & 9.15 & 2.91 & -0.01 & $0.36^{* * *}$ & 1.00 & & & & & \\
4.Racial Opt. & 9.17 & 2.56 & $0.16^{*}$ & -0.01 & $0.13^{*}$ & 1.00 & & & & \\
5.Self-esteem & 54.35 & 11.74 & $0.64^{* * * *}$ & $-0.28^{* * *}$ & $0.13^{*}$ & $0.17^{* *}$ & 1.00 & & & \\
6.Stress & 37.30 & 6.67 & $-0.34^{* * *}$ & $0.29^{* * *}$ & $0.19^{* *}$ & -0.04 & $-0.34^{* * *}$ & 1.00 & & \\
7.Identity & 76.75 & 18.86 & $0.33^{* * *}$ & -.06 & $.13^{*}$ & $0.14^{*}$ & $0.27^{* * *}$ & 0.03 & 1.00 & \\
8.Residence & 45.81 & 12.84 & $0.25^{* * *}$ & -.07 & -.03 & -0.02 & $0.19^{* *}$ & -0.04 & $0.30^{* * *}$ & 1.00 \\
\hline
\end{tabular}

Note. Satisfy=college life satisfaction; External=external control; Racial Pes. (Racial pessimism)=anti-racist pessimism or racism as an unsolvable problem (i.e., racism is stable and permanent); Racial Opt. (i.e., racial optimism)=anti-racist optimism or racism as a solvable problem through social pressure; Self-Esteem=Individual self-esteem or personal identity; Stress=perceived stress; Identity=social identity or collective or group self-esteem; and Residence $=$ measurement of residential conditions.

${ }^{*} \mathrm{p}<.05 ; * * \mathrm{p}<.01 ; * * * \mathrm{p}<.001 ; * * * * \mathrm{p}<.0001$

Moreover, greater external control was related to greater anti-racist pessimism (i.e., stability or permanence of racism), and also related to lower individual self-esteem (or personal identity) and to greater perceived stress. Greater individual self-esteem (i.e., personal identity) was related to greater collective self-esteem (i.e., social identity). In other words, those who scored high in personal identity scored high in social identity.

In addition to the relationship between perceived stress, college life satisfaction and external control, there were significant correlations between perceived stress and pessimistic attitudes toward reducing racism and solving racial problems, $r=0.19, p<0.01$, two-tailed, and between perceived stress and individual self-esteem, $r=-0.34, p<0.001$, two-tailed. In other words, the greater the perceived stress, the more pessimistic attitudes were toward solving racial problems; and the greater the perceived stress, the lower the individual self-esteem (or personal identity).

\subsection{Predictors of Life Satisfaction by Stepwise Multiple Regression Analysis}

Although the results in Table 1 provide us with basic intercorrelations, they do not precisely predict college life satisfaction. Thus, all predicting variables should be considered in the regression equation to determine how college life satisfaction can be predicted by all the variables in this study. In other words, in the regression analysis, college life satisfaction was a predicted variable while self-esteem, stress, social identity, residential conditions, racial (or anti-racist) pessimism, racial (or anti-racist) optimism and internal-external locus of control were used as predictors or independent variables, in the equation. This easily shows how the variance in the criterion variable is shared by predicting variables.

By stepwise multiple regression analysis, it was found that higher self-esteem (Multiple $R=0.63, R^{2}=0.40$, Adjusted $R^{2}=0.40$ ) and lower stress (Multiple $R=0.34, R^{2}=0.12$, Adjusted $R^{2}=0.11$ ) accounted most for the variance of life satisfaction (see Table 2). While social identity (Multiple $R=0.32, R^{2}=0.10$, Adjusted $R^{2}=0.10$ ) also explained $10 \%$ of the variance in the criterion variable.

Table 2. College Life Satisfaction as a Predicted Variable: Stepwise Multiple Regression Analysis

\begin{tabular}{cccccccccc}
\hline & & \multicolumn{3}{c}{ Adjusted } & \multicolumn{4}{c}{ Variables in the equation } \\
& Multiple R & $\mathrm{R}^{2}$ & $\mathrm{R}^{2}$ & $\mathrm{~B}$ & $\mathrm{SE} \mathrm{B}$ & Beta & $\mathrm{F}$ & $\mathrm{P}$ \\
\hline 1. Self-esteem & 0.63 & 0.40 & 0.40 & 0.32 & 0.04 & 0.54 & 8.14 & 0.0000 \\
2.identity & 0.32 & 0.10 & 0.10 & 0.06 & 0.022 & 0.17 & 2.82 & 0.005 \\
3.stress & 0.34 & 0.12 & 0.11 & -0.16 & 0.06 & -0.16 & -2.52 & 0.013 \\
4.Residence & 0.23 & 0.06 & 0.05 & 0.04 & 0.03 & 0.08 & 1.47 & 0.145 \\
5.Racial Pessimism & 0.007 & 0.0001 & -0.000 & -0.19 & 0.14 & -0.08 & -1.32 & 0.188 \\
6.Racial Optimism & 0.15 & 0.024 & 0.02 & 0.15 & 0.15 & 0.06 & 0.996 & 0.321 \\
7.External & 0.21 & 0.04 & 0.04 & 0.01 & 0.02 & 0.03 & 0.55 & 0.58 \\
\hline
\end{tabular}

Note: Self-esteem=individuality self-esteem or personal identity; Identity=social identity or collective/group self-esteem; Stress=perceived stress; Residence=measurement of residential conditions; Racial pessimism=anti-racist pessimism or racism as an unsolvable problem (i.e., racism is stable and permanent); Racial optimism=anti-racist optimism or racism as a solvable problem through social pressure; and External=external control . 
Inspection of the beta values revealed the following pattern: self-esteem $(\beta=.54, p<0.0001)$, stress $(\beta=-.16, p<$ $0.01)$, social identity $(\beta=0.17, p<0.005)$, residential conditions $(\beta=0.08$, ns), racial (or anti-racist) pessimism $(\beta=$ $0.07, \mathrm{~ns})$, and internal-external control $(\beta=0.04, \mathrm{~ns})$. These data indicated that higher self-esteem, lower stress and greater positive group image or pride were significantly related to greater life satisfaction at colleges whereas variables such as residential conditions, locus of control, and racial attitudes were not significant, which was consistent with the hypothesis above.

\subsection{Ethnic Differences}

The data for college life satisfaction revealed the considerable differences between various ethnic groups, $F(3,182)$ $=9.85, p<0.0001$. White students were more satisfied with college life than Hispanic, African, and Asian students (see Table 3). Examination of the data in the table suggests that the difference between the ethnic groups was significant regarding individual self-esteem (or personal identity), $F(3,182)=10.58, p<0.00001$, and collective self-esteem (or social identity), $F(3,182)=5.23, p<0.001$. That is, White students, African and Hispanic students scored higher in individual self-esteem (or personal identity) and collective self-esteem (or social identity) than did Asian students.

Table 3. Mean Scores between Different Ethnic Groups

\begin{tabular}{ccccccc}
\hline & $\begin{array}{c}\text { White } \\
(\mathrm{n}=102)\end{array}$ & $\begin{array}{c}\text { Blk/His* } \\
(\mathrm{n}=21)\end{array}$ & $\begin{array}{c}\text { Asian } \\
(\mathrm{n}=37)\end{array}$ & $\begin{array}{c}\text { Other } \\
(\mathrm{n}=26)\end{array}$ & $\begin{array}{c}\mathrm{F} \\
(3,182)\end{array}$ & $\mathrm{P}$ \\
\hline Satisfy & 48.67 & $46.05^{\mathrm{a}}$ & 40.43 & $44^{\mathrm{a}}$ & 9.85 & 0.0000 \\
Self-esteem & $56.55^{\mathrm{b}}$ & $61.05^{\mathrm{b}}$ & $46.95^{\mathrm{a}}$ & $50.85^{\mathrm{a}}$ & 10.58 & 0.0000 \\
Identity & $80.37^{\mathrm{a}}$ & $80.62^{\mathrm{ab}}$ & $67.65^{\mathrm{c}}$ & $72.35^{\mathrm{bc}}$ & 5.23 & 0.001 \\
Stress & $37.72^{\mathrm{a}}$ & $35.29^{\mathrm{a}}$ & $38.21^{\mathrm{a}}$ & $36.15^{\mathrm{a}}$ & 1.24 & 0.29 \\
Residence & $49.12^{\mathrm{a}}$ & $48.15^{\mathrm{a}}$ & $41.27^{\mathrm{b}}$ & $37.39^{\mathrm{b}}$ & 8.74 & 0.000 \\
Racial Pes. & $9.51^{\mathrm{bc}}$ & $8.95^{\mathrm{abd}}$ & $9.32^{\mathrm{ac}}$ & $7.61^{\mathrm{d}}$ & 3.10 & 0.03 \\
Racial Opt. & $9.13^{\mathrm{ab}}$ & $10.23^{\mathrm{c}}$ & $8.70^{\mathrm{ad}}$ & $9.12^{\mathrm{bcd}}$ & 3.10 & 0.17 \\
External & $114.07^{\mathrm{ab}}$ & $105.95^{\mathrm{c}}$ & $119.59^{\text {ad }}$ & $109.23^{\mathrm{bcd}}$ & 2.61 & 0.05 \\
\hline
\end{tabular}

* Blk=Black/African Americans; His=Hispanic Americans

Note. Satisfy=college life satisfaction; Self-esteem=individual self-esteem or personal identity; Identity=social identity or collective/group self-esteem; Stress=perceived stress; Residence=measurement of residential conditions; Racial Pes.(i.e., pessimism )= anti-racist pessimism or racism as an unsolvable problem (i.e., racism is stable and permanent); Racial Opt. (i.e., optimism) $=$ anti-racist optimism or racism as a solvable problem through social pressure; and External=external control. The mean numbers with the identical superscripts indicate that they are not significant at the 0.05 level.

Additionally, results for students' living or residential conditions revealed an ethnic difference, $F(3,182)=8.74$, $p<0.001$. White, Hispanic and African Students felt more satisfied with their living conditions than did Asian and other students on campus. The difference between various ethnic groups was also found to be significant for locus of control, $F(3,182)=2.61, p<0.05$, with higher externality in Table 3 indicating less internal control. Finally, regarding their racial (or anti-racist) pessimism (i.e., "racism as an unsolvable problem," and "racism is stable and permanent"), White students strongly agreed, Asian student moderately agreed, and Hispanic and African students moderately disagreed and other students strongly disagreed, $F(3,182)=3.10, p=0.03$.

\section{Discussion}

Overall life satisfaction among college students was mainly predicted from such variables as personal identity, social identity, and stress. It was also found that there were considerable differences between various ethnic groups in terms of their college life satisfaction, personal identity and social identity and other variables.

The current study further confirmed that individual self-esteem (or personal identity) and individual stress were important predictors of life adjustment and satisfaction. However, as social beings, social identity (i.e., collective self-esteem) was also found to be important in accounting for college life satisfaction, which is an extension of the previous research (see Aspinwall \& S. Taylor, 1992; Mooney, Sherman \& Presto, 1991). Moreover, it was found that there were considerable differences between White, Hispanic, African, Asian, and other students in their college life satisfaction, personal identity, social identity, locus of control, residence or living conditions, as well as attitudes toward racism 
and racial problems on campus.

The results provide strong evidence in support of social identity theory rather than for the "melting pot" political philosophy (see Lee \& Holt, 2019; Lee \& Zhao, 2019). Specifically, each group has its own unique cultures and differences. These differences and distinctions cannot be assimilated into the same great pot because social group members are motivated to maintain and protect not only their personal identity (i.e., individual self-esteem), but also their social identity (i.e., collective self-esteem or positive image for their own group). These two identities cannot be separated from one another. Social identity theory places great emphasis upon the individual's dependence upon, or reference to, a group or category (also see Brown, 1988; Rule \& Sutherland, 2017), but not upon the independence of individuals from a group. In other words, social identity theory holds that self-concept or personal identity cannot exist without reference to a group. Clearly, collective self-esteem (i.e., social identity) is as important as, if not more important than, individual self-esteem (i.e., personal identity).

A question arises; though social identity theory (Tajfel, 1981; Tajfel \& Turner, 1986) holds that members of a social group are motivated to be distinctive from members of other groups so as to maintain positive image for their group, how then, do group members (e.g., ethnically different students) protect the positive image of their own group? According to Tajfel and Turner (1986), Tajfel (1982), there are several strategies that serve to protect or enhance social identity. First, social comparison or competition, whereby the group members work together and try to enhance their objective position in the society (e.g., social change or voice). Second, individual mobility, whereby persons who are not satisfied with their groups leave or exit from their group (i.e., social mobility or exit). But this strategy is hard to adopt because many individuals do not want to be regarded as traitors or renegades to their group. Third, is an individual's comparison of the ingroup with the outgroup along dimensions that allow for a positive outcome; for example, a Chinese may choose to compare Chinese Americans with White Americans on how well they cook rather than how politically influential they are in America. The fourth strategy is to change the values assigned to the characteristics of the ingroup so that previously negative characteristics are now perceived as positive, for instance, "Black is beautiful" (Tajfel, 1981).

In a sense, the present findings are consistent with a preliminary model of group formation and development (Worchel, Coutant-Sassic, \& Grossman, 1991). Worchel and his colleagues have argued that group members who are discontent with a parent group (supercategory) tend to break away from the parent group and form their own groups (subcategories) with their own identity. During the Persian Gulf war, it was found that social identity played an important role in ethnically different students' attitudes toward the war (see Lee, 1993a). Specifically, minority students showed much less patriotic and nationalistic attitudes toward the United States than did their nonminority counterparts. They were less in favor of Bush and more supportive of a peaceful solution to the conflict even during the Gulf war. Even during the war, minority students tended to develop their own identities and maintain their subcultures in American society.

A cautionary note should be taken. Perceived stress is one of the major predictors in college life satisfaction. According to Cohen, Kamarck, Mermelestein (1983), perceived stress means a psychological pressure that involves potential harmful life events which can challenge an organism. In brief, stress is a psychological and physiological reaction to life events. Of interest, perceived stress was correlated with personal identity (i.e., individual self-esteem) but not significantly related to social identity (i.e., collective/group self-esteem). This begs the question, "Why is stress more correlated with personal identity than with social identity?” This finding needs more attention in future research.

What are some of the implications of this study? First, the findings in this research provide support for the social identity theory rather than the "melting pot" philosophy. By applying social identity theory to the area of college student counseling and development, the study here is of both theoretical and practical significance.

Second, the results obtained here suggest that students are not separate entities but part of social groups. Social/group identity and personal identity jointly play an important role in their college life satisfaction and adjustment. From this perspective, the current findings are not only an extension of previous results (see Aspinwall \& S. Taylor, 1992; Mooney, Sherman \& Presto, 1991), but also a new contribution to the field of college student counseling and development.

Finally, while we acknowledge that more research on these areas is needed in the future, the current study provides more evidence for the consideration of cultural sensitivity and pluralism in college counseling and development. This is also consistent with other recent research (see Lee \& Zhao, 2019; Rule \& Sutherland, 2017). As college staff and faculty members, or as college administrators and counselors, we may have to be aware that the "melting pot" political philosophy may be psychologically or socially harmful to our students; and that social identity (e.g., cultural heritage, symbolic values, and positive image) is of major importance to students at American colleges today. A finding which is also consistent with the humanistic and Daoist philosophy (Lee \& Holt, 2019; also see Lee, 2011; Lee, 2019).

In conclusion, social identity, and cultural pluralism, to a certain extent, play an important role in college life satis- 
faction and may influence the behavior and attitudes of college students. Just as we consider the impact of individual self-esteem (or personal identity), stress and anxiety, financial and living conditions, and academic performance on college life satisfaction, so we cannot avoid thinking of the impact of social and cultural identity (e.g., heritage, values, racism, and ingroup homogeneity or cohesiveness) on college life satisfaction (see Lee, 1993b). In contrast to other studies (e.g., Aspinwall \& Taylor, 1992; Mooney, Sherman \& Presto, 1991), locus of control in this study was not perceived to be so important as personal and social identity in explaining college life satisfaction. Consistent with social identity theory, the differences between various ethnic groups were found to be significant in their college life satisfaction, personal identity, social identity, locus of control, residence or living conditions, and pessimistic attitudes toward racial problems. In conclusion, personal identity, social identity, and perceived stress account for most of college life satisfaction.

\section{Acknowledgement}

The data reported in this study were collected before 2018. We appreciate Dr. Lee's colleagues Ivan Ernest and Hanh Huy Phan and his research lab team members for their help and assistance in this research project.

\section{References}

Aronson, E. (1992). Social animal. New York: W. H. Freeman \& Co.

Aspinwall, L. G. and Taylor, S. E. (1992). Modeling cognitive adaption: A longitudinal investigation of the impact of individual differences and coping on college adjustment and performance. Journal of Personality and Social Psychology, 63, 989-1003.

Berger, J. (1989, May 22). Racial strains show two perspectives on inequality. New York Times.

Brewer, M. B. (1991). The social self: On being the same and different at the same time. Personality and Social Psychology Bulletin, $17,475-482$.

Brown, R. J. (1988). Group processes: Dynamics within and between groups. New York: Basil Blackwell Ltd.

Cantril, H. (1965). The pattern of human concerns. New Brunswick, NJ: Rutgers University Press.

Cohen, S., Kamarck, T., and Mermelstein, R. (1983). A global measure of perceived stress. Journal of Health and Social Behavior, 24, 385-396.

Crocker, J. (2002). The costs of seeking self-esteem. Journal of Social Issues, 58(3), 597-615.

Crocker, J. and Luhtanen, R. (1990). Collective self-esteem and in-group bias. Journal of Personality and Social Psychology, 58(1), 60-67.

Crocker, J. and Wolfe, C. T. (2001). Contingencies of self-worth. Psychological Review, 108, 593-623.

Cronbach, L. J. (1951). Coefficient alpha and internal structure of tests. Psychometrika, 16, 297-334.

Fisher, A., Fisher, S. Arsenault, C., Jacob, R., and Najor, J. (2020). The Moderating Role of Ethnic Identity on the Relationship Between School Climate and Self-Esteem for African American Adolescents. School Psychology Review, 49(3), $291-305$.

James, W. H. (1957). Internal versus external control of reinforcement as a basic variable in learning theory. Unpublished doctoral dissertation. Ohio State University.

Lee, Y. T. (1993a). Reaction of American minority and nonminority students to the Persian Gulf war. The Journal of Social Psychology, 133, 707-713.

Lee, Y. T. (1993b). Ingroup preference and homogeneity among African American and Chinese American students. The Journal of Social Psychology, 132, 225-235.

Lee, Y. T. (1994). Racial Conflict in Academic Communities: An Analysis of Various Forms of Racism and Prejudice. IMPART: Journal of Open Mind (in press). 2, 78-86.

Lee, Y-T. (2011). Social Psychology of Stereotyping and Human Difference Appreciation. In S. Chen (ed.), Diversity management: Theoretical perspectives, practical approaches, and academic leadership (pp.33-46). New York, NY: Nova Science Publishers, Inc.

Lee, Y-T. (2019). What can professionals learn from Daoist philosophy? Application of Daoist ideas to therapy and administration Lee, Y-T. \& Holt, L. B. Eds. (2019). Dao and Daoist ideas for scientists, humanists, and practitioners. Hauppauge, NY: Nova Science Publishers, Inc.

Lee, Y. T. and Ottati, V. (1993). Determinants of Ingroup and Outgroup Perceptions of Heterogeneity: An Investigation of Si- 
no-American Stereotypes. Journal of Cross-Cultural Psychology, 24, 298-318.

Lee, Y-T. and Seligman, M. E. P. (1997). Are Americans more optimistic than the Chinese? Personality and Social Psychology Bulletin, 23(1), 32-40.

Lee, Y-T. and Zhao, Y. (2019). Ancient Daoist perspectives and modern stereotype research as approaches to diversity management and human differences appreciation. In Y-T Lee \& L. Holt (eds.), Dao and Daoist ideas for scientists, humanists, and practitioners. Hauppauge, NY: Nova Science Publishers, Inc.

Luhtanen, R. and Crocker, J. (1992). A collective self-esteem scale: self-evaluation of one's social identity. Personality and Social Psychology Bulletin, 18, 302-318.

McConahay, J. B. and Hough, J. C. (1976). Symbolic racism. Journal of Social Issues, 32(2), 23-45.

Mooney, S. P., Sherman, M. F., and Lo Presto, C. T (1991). Academic locus of control, self-esteem, and perceived distance from home as predictors of college adjustment. Journal of Counselling and Development, 69, 445-448.

Rosenberg, M. (1965). Society and adolescent self-image. Princeton, NJ: Princeton University Press.

Rule, O. N. and Sutherland, S. L. (2017). Social categorization from faces: Evidence from obvious and ambiguous groups. Current Directions in Psychological Science, 26(3), 231-236.

Sears, D. O. (1988). Symbolic racism. In P. A. Katz, \& D. A. Taylor (eds.), Eliminating racism: Profiles in controversy. New York: Plenum Press.

Sears, D. O., Huddy, L., and Schaffer, L. (1986). A schematic variant of symbolic political theory as applied to racial and gender equality. In R. R. Lau \& D. O. Sears (eds.), Political Cognition. Hillsdale, NJ: Lawrence Erlbaum Associates, Publishers.

Tajfel, H. (1981). Human groups and social categories. Cambridge: Cambridge Univ. Press.

Tajfel, H. (1982). Social psychology of intergroup relations. Annual Review of Psychology, 33, 1-39.

Tajfel, H. and Turner, J. C. (1986). The social identity theory of intergroup behavior. In S. Worchel \& W. G. Austin (Eds.), Psychology of intergroup relations. Chicago: Nelson-Hall.

Taylor, D. M. and Dube, L. (1986). Two faces of identity: The "I" and the "We”. Journal of Social Issues, 42(2), 81-98.

Taylor, D. M. and Porter, L. (1994). A multicultural view of stereotyping. In W. J. Lonner \& R. Malpass, (eds.), Psychology and culture. Boston, MA: Allyn \& Bacon.

Taylor, D. M., Wright, S. C., Moghaddam, F. M., and Lalonde, R. N. (1990). The personal and group discrimination discrepancy: Perceiving my group, but not myself, to be a target for discrimination. Personality and Social Psychology Bulletin, 16, 254-262.

Wang, Y. Y., Sedlacek, W. E., and Westbrook, F. D. (1992). Asian Americans and student organizations: Attitudes and participation. Journal of College Student Development, 33, 214-221.

Worchel, S., Coutant-Sassic, D., and Grossman, M. (1991). A developmental approach to group dynamics: A model and illustrative research. In S. Worchel, W. Wood, \& J. Simpson (Eds.), Group process and productivity. Newbury Park, CA: Sage Publishing.

Yau, T. Y., Sue, D., and Hayden, D. (1992). Counseling style preference of international students. Journal of Counseling Psychology, 39, 100-104. 